\title{
TEACHING CASE COMBINED DISCIPLINE CAPSTONE TEAMS: USING SERVICE LEARNING TO PROVIDE A BUSINESS SOLUTION
}

\author{
K. David Smith, Cameron University, davids@cameron.edu \\ Mike Estep, Cameron University, mestep@cameron.edu \\ Chao Zhao, Cameron University, chaoz@cameron.edu \\ Feridoon Moinian, Cameron University, feridoon@cameron.edu \\ Abbas Johari, Cameron University, abbasj@cameron.edu
}

\begin{abstract}
Computing faculty from a regional university in Oklahoma implemented a plan to combine undergraduate capstone courses in Management Information Systems (MIS), Computer Science (CS), and Multimedia (MM). The MIS course had been using experiential service learning and completing small database projects for local organizations since 2003. Based on the experiences and contacts of the MIS faculty, a decision was made to conduct an actual business related project. The project chosen was one for the alumni association of a local high school. They required a web presence and wanted something akin to Classmates.com. Originally, the alumni association contracted the project through a local commercial company. However, after one year of trying to get the local company to deliver what was needed, the alumni association contacted the MIS faculty for help in developing the site. The project required an appealing and easy to use front-end interface, a back-end database, and middleware to connect the two. The MIS class was assigned to create the database. The CS class wrote the middleware using PHP with the MIS class assisted with imbedded MySQL statements. The MM class created the front-end user interface. This teaching case presents the experiences, results, and conclusions of the project.
\end{abstract}

Keywords: Capstone, Service Learning, Teamwork, PHP, MySQL

\section{INTRODUCTION}

A capstone course is designed to help students integrate their knowledge to solve a substantial problem in their study field $[3,12]$. However, the authors wanted to determine how capstone courses could be taught more effectively in terms of problem solving, analytical and critical thinking, teamwork, and technical skills. The authors have experimented in past semesters with different approaches, including projects and project/lecture combination. Based on success from these approaches, one of the authors suggested combining capstone courses in Computer Science (CS), Management Information Systems (MIS), and Multimedia (MM) together to provide students with a multiple discipline environment where the students could learn more and do more. The idea was supported by faculty and administrators at the authors' affiliated university. Therefore, the focus of this project encompasses the teaching, design, and analysis of information from this capstone approach.

The project chosen was one for the alumni association of a local 6A high school. They required a web presence and wanted something akin to Classmates.com [2]. Originally, the project was contracted through a local commercial company. However, after one unsuccessful year of trying to get the local company to deliver what was needed, the alumni association contacted the MIS faculty for help in developing the site. The project required an appealing and easy to use front-end interface, a back-end database, and middleware to connect the two. The MIS class was assigned to create the database. The CS class would write the middleware using PHP with the MIS class assisting with imbedded MySQL statements. The MM class would create the front-end user interface.

The authors scheduled the capstone classes at the same time under departmental support. Students who were from MIS, CS, and MM were divided into two teams according to instructor-predefined procedures. Once teams were formed, team members started to work together. Teaching strategy involved the spring semester being divided into two phases: instruction phase and project phase. The instruction phase focused on: (a) software engineering basics, (b) project analysis and design, (c) project management, (d) interviewing client representatives, and (e) learning how to use CASE tools. The project phase focused on technical skills and project completion. After this practice, it was discovered that the students involved seemed very interested in the real world and multiple discipline environment, 


\section{Issues in Information Systems \\ Volume 15, Issue II, pp. 8-13, 2014}

where they felt motivated and learned much in both their own discipline and other disciplines. Meanwhile their technical skills and communication skills were enhanced.

\section{LITERATURE REVIEW}

Organizations commonly use teamwork to achieve their goals effectively. There is also a significant amount of published reports on the importance of teamwork and the elements that contribute to forming successful teams [4, 13]. According to Murphy [7], workers in complex manufacturing environments have the most to gain from the use of problem-solving teams. Using data from steel minimills, the study shows that teams had the greatest impact if they tackled complex tasks in these environments, enjoyed meaningful incentives, and knew that management listened to them.

To better prepare students for today's complex and challenging workplace, academia has also recognized the importance of exposing students to teamwork environments. For example, the Penn State University alumni recommended that the Penn State undergraduate education should include more teamwork experience. As a result, the general education requirements now include an active learning elements component, which can be satisfied by a "collaborative learning and teamwork" element [8]. According to this initiative, through teamwork, organizations can accomplish complex projects more efficiently than individuals can, as team members brainstorm more solution options. Flaws can be better detected in solutions, and personal bonding can form among students that will enrich their learning experience and extend beyond the classroom.

Many academic disciplines also include a capstone component in their curriculum to provide a real-world experience to students. However, it is common practice that most capstone course student teams belong to the same discipline and team members have similar backgrounds and technical skills. Although students experience the benefits and drawbacks of working in teams for solving complex problems, they often do not get a chance to work with students from adjacent disciplines with varying backgrounds [11]. The authors have found the task challenging in determining how to combine capstone courses from different disciplines to create a single class where students with different majors can work together to solve a real-world problem.

A main reason for this challenge has to do with the physical separation of computing disciplines across campuses. For example, CS departments have historically been separate departments, or have been a part of mathematics or engineering schools. Furthermore, MIS departments have usually been mixed with business schools, but not with MM $[9,10]$. The historical separation of CS, MIS, and MM have likely made it difficult for academics to conceive the notion of collaboration within the corresponding capstone courses. Fortunately, the Computing and Technology department at the authors' affiliated university offers multiple computing-related academic programs which provide the faculty a unique environment to study the possibility and benefits of a combined capstone course. The authors' practice indicates that the combined capstone course creates a rich and innovative real-world learning environment, where students from different disciplines learn from each other to achieve better-than-expected learning outcomes.

Another reason for the challenge involves the complexity of managing a combined cross-discipline capstone course. Such management requires a close relationship among the faculty within different disciplines to be willing to work together, and may also require the involvement of different department administrators in organizing and scheduling such capstone courses [11]. Due to the stated reasons, there seems to be minimal published reports from undergraduate schools who have attempted experimenting with such projects.

On the other hand, some graduate schools have undertaken the cross-discipline merging of capstone courses and have reported the results of their experiences. For example, in one case study, graduate students from a Master of Business Administration course were teamed with students from a Master of Accounting course to work on an interdisciplinary group technical project [6]. The case study found that creating teamwork collaboration across disciplines allows students to obtain skills needed to become effective members of work teams. Students also learn from their interactions with other students, and such projects are even beneficial to the faculty who are involved in those courses. Although the course management requires a significant amount of time for communication and coordination, it also provides faculty with the satisfaction of creating and working in a synergistic environment. 


\section{Issues in Information Systems \\ Volume 15, Issue II, pp. 8-13, 2014}

\section{METHODOLOGY}

First, the number of teams was determined based on the amount of students in the smallest class. Then teams were decided based on resumes, cover letters, and skills assessments. A project manager was chosen for each MIS and CS team by the various faculty members. These project managers were then given a blind copy of each student's resume, cover letter, and skills assessment. The project managers went to a closed room and (blindly) determined who would be on their teams. MIS and CS teams were then integrated. The single MM team acted as a "contractor" and worked for both teams.

After teams were determined, they were given one class period to prepare for a client brief. The client then briefed the combined classes as to their needs/desires and answered what questions the combined teams asked. Immediately after, following the question-answer period, the classes separated until the halfway point in the 16-week semester.

During the first 8 weeks, the MIS teams, using information gleaned from the client, designed the database. The teams used Rational System Architect [5] as the CASE tool for developing all models, data flow diagrams, etc. At week 6, they held a formal briefing with the client called an In Process Review (IPR), and the MIS teams made presentations. Each team briefed the logical model of the database (Figure 1). Based on feedback from the client at the IPR, each MIS team completed its own design and implemented that design in MySQL.

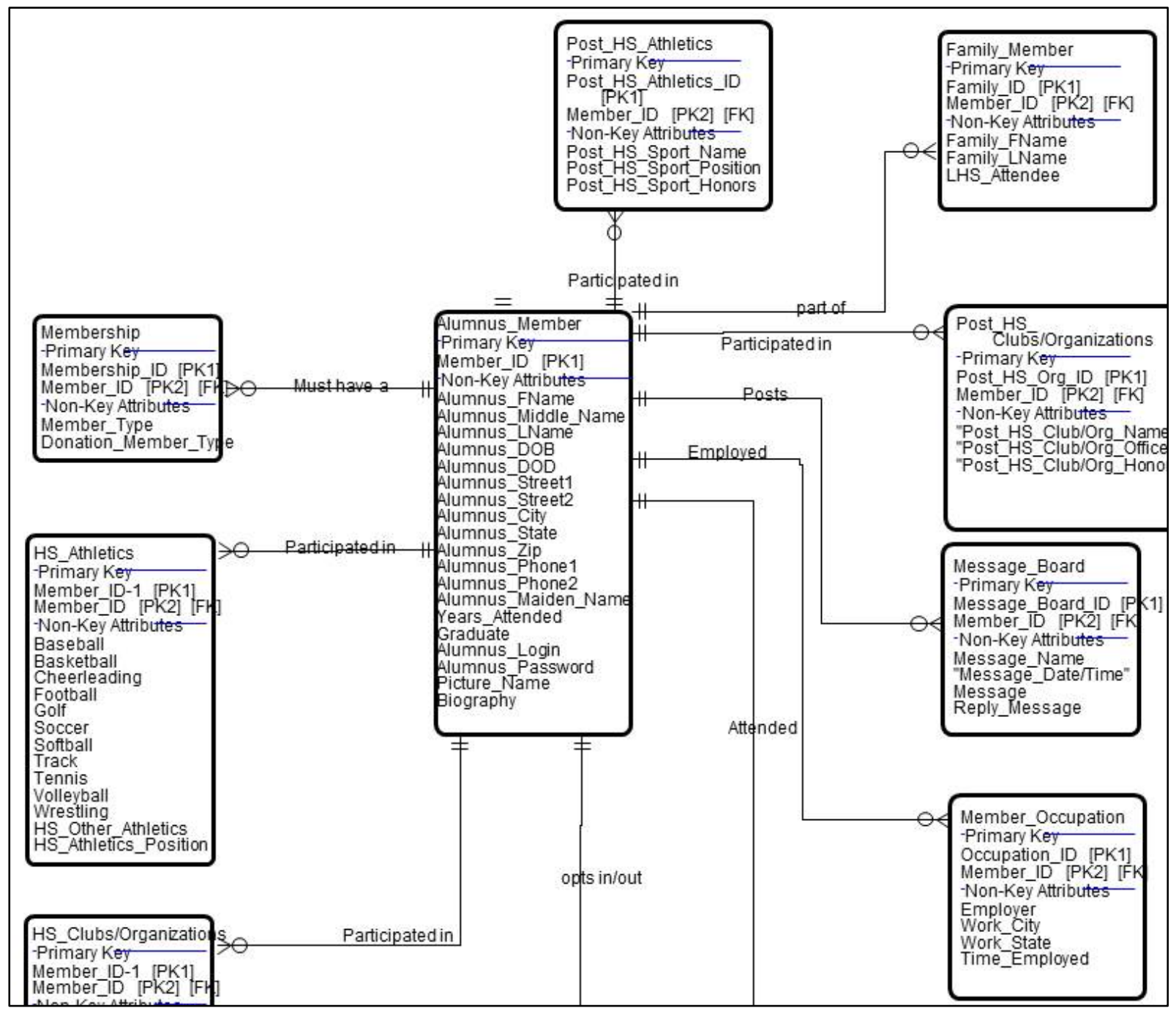

Figure 1: Example Partial Logical Model 
At week 8, the MIS and CS teams integrated for the remainder of the semester. During the last half of the semester, each combined team worked on their own solution. A proof-of-concept version of the final product was demonstrated to the client during week 12 by the CS students (Figure 2 - Middleware) and MM students. Some basic functionality was demonstrated at that time. Based on feedback from the client to each team, the teams then worked to complete the project. It should be noted, that a completed functional product was required for passing the class. The final project was presented to the client by each team as the final exam.

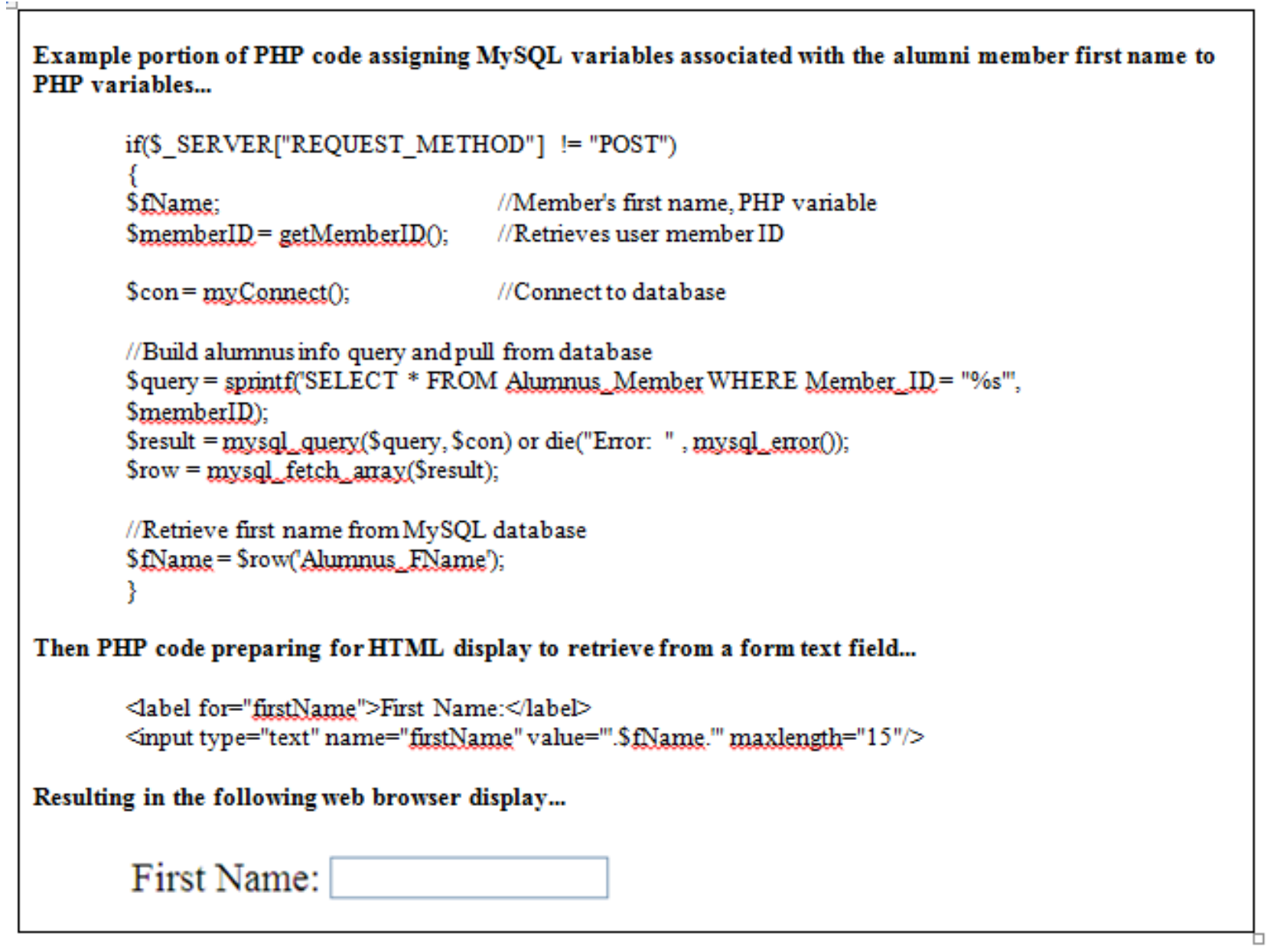

Figure 2: Example PHP Middleware

\section{RESULTS}

\section{Client Perspective}

The alumni association participated in the final exam, which consisted of student teams demonstrating the completed project. They then chose the "winning" team. All source code was provided to the clients. Members of the winning team uploaded files via FTP to the client's server. The clients indicated that: (1) they found the process to be professional, (2) there was excellent communication between the students and themselves, (3) the IPRs were very important to the process and there should be at least one additional IPR added to the schedule, and (4) the project was a success. The website was put into service, and the clients have indicated that they were satisfied with the product. All students that participated in the project received a letter of recommendation from the client as "payment" for their services. 


\section{Student Perspective}

Overall, the students viewed the project as a success. At graduation, one CS student conveyed the following to the MIS faculty member:

- "Mr. (MIS Faculty member), I hated you during that class. It was so time consuming. However, I love you now. I just landed a very good job, largely due to that class."

Additional comments from the end of course student survey included:

- “...the combined capstone project is an excellent idea. ... this will prove to be a very valuable experience to the three departments. It provides a real-world experience to all the students involved."

- "The course is more real-world oriented and therefore better prepares students for the work field. Plus, various communications skills are better honed during the project development."

- "I think this should be the wave of the future. It's the type of environment students will work in when they are employed by industry."

- "This was a very good class in regards to a setting that resembled the real business world. It gave us all a taste of the difficulties a team could encounter, and then overcoming them."

- "I think that this approach exposes student to real-life work experiences. Team integration helps students interact with colleagues and learn how to delegate and share responsibilities."

Still, not every student appreciated this approach, and there were a few negative comments such as:

- "I did not like the two-team approach. I believe that no teams should have been formed to complete this project. All students working together would have provided a much better learning experience, which is what should be the main goal of this course. Instead, the project was turned into a promotional project for Cameron, at the expense of the students."

- "I think that more effort from the instructors needs to be given when organizing for this course."

- "Nothing... I feel like a lost 5 years of my life" (answering what the student liked most about the class).

Even so, the majority (94\%) of the students felt that the class and the project was interesting and stimulating. $83 \%$ would recommend the class to others. $72 \%$ felt they had a stronger interest in their program due to the course. $83 \%$ believed that the combined capstone approach was beneficial to them learning to work in teams. $77.78 \%$ believed that the combined capstone approach improved their collaboration skills. The most interesting descriptive statistics from the class survey had to do with their satisfaction with the combined capstone approach. Likert scale answers included: $16.67 \%$ were extremely satisfied with the approach, $38.89 \%$ were satisfied with the approach, $27.78 \%$ were neither satisfied nor dissatisfied with the approach, 5.56\% were dissatisfied, and $11.11 \%$ were extremely dissatisfied with the approach. Reasons for the dissatisfaction seemed to be centered on several areas: first, on the amount of time required to complete the project; and secondly, on the fact that some students did not work as hard as others throughout the course.

\section{Faculty Perspective}

Based upon this project, the faculty members believe the integrated team approach provided realism to the classes that is not possible with textbook exercises alone. There have now been several iterations of the combined capstone with successful results. The faculty have since added another related discipline (computer information systems) to the combined team approach, and a technical writer for each team from the English and Foreign Language Department. It has been the faculty experience that the students involved in these combined capstone courses are marketable in the competitive computing industry, as the type of systems work is what computing professionals actually encounter in industry.

\section{University Perspective}

The authors' affiliated university is highly interested in service learning. Service learning projects are tracked through AmeriCorps VISTA volunteers [1] and a university service learning committee. The Assistant Vice President of Academic Affairs was shown the systems analysis and design implementation book for one of the teams. She asked to use it as an example for other departments. 


\section{Issues in Information Systems \\ Volume 15, Issue II, pp. 8-13, 2014}

\section{CONCLUSIONS}

The biggest challenge of a project of this type is related to soft skills. Specifically, communication, coordination, and project management skills were problematic. For students, inter-team communications at times caused friction between various teammates. For example due to differences in CS, MIS, and MM backgrounds, students often encountered delays that necessitated faculty intervention and guidance. Also, at times the clients were unsure how to explain what they needed. This tended to cause confusion and scope creep throughout the project.

From the above combined capstone class teaching practice, the authors conclude that the service learning combined capstone approach appears to be an efficient way to teach a capstone class where the instructors acted as both teacher and "CEO" of the combined project, such that the instructors also learned about project management and resource management. Meanwhile, the combined capstone class covered different disciplines where the instructors must learn from each other in order to understand the comprehensive combined project, which is a good way to carry out cross-discipline instructor training. The students appear to appreciate the combined capstone class approach, where they applied their knowledge learned from previous classes to solve a real problem. They also learned new knowledge and how to work with others who are from different disciplines in a way that cannot be learned in a typical classroom setting. In summary, the combined capstone class is likely a meaningful approach for teaching capstone courses where both student learning and instructor training are enhanced.

\section{REFERENCES}

1. AmeriCorps (2013). AmeriCorps VISTA. Retrieved August 12, 2013, from http://www.americorps.gov/about/programs/vista.asp.

2. Classmates.com (2013). Step Back in Time-Classmates.com. Retrieved August 12, 2013, from http://www.classmates.com/.

3. Dugan, R.F. (2011). A survey of computer science capstone literature. Computer Science Education, 21(3), 201-267.

4. Google Scholar (2013). A search on the term "Teamwork," Retrieved August 12, 2013, from http://scholar.google.com/scholar?hl=en\&q=teamwork\&as_sdt=0\%2C37\&as_ylo=\&as_vis $=0$.

5. IBM (2013). Rational System Architect, Retrieved August 12, 2013, from http://www01.ibm.com/software/awdtools/systemarchitect/.

6. Kruck, S.E. \& Teer, F.P. (2009). Interdisciplinary student team projects: A case study. Journal of Information Systems Education, 20(3), 325-330.

7. Murphy, D. (2008). Teamwork Can Boost Manufacturing Productivity. Retrieved August 12, 2013, from http://www.gsb.stanford.edu/news/research/shawteams.shtml.

8. Penn State University (2001). Active Learning Elements in General Education Courses. Retrieved August 12, 2013, from http://tlt.its.psu.edu/suggestions/teams/about/benefits.html.

9. Reichgelt, H., Lunt, B., Ashford, T., Phelps, A., Slazinski, E., \& Willis, C. (2004). A comparison of baccalaureate programs in information technology with baccalaureate programs in computer science and information systems. Journal of Information Technology Education, 3, 19-34.

10. Shackelford. R., Cross, J., Davies, G., Impagliazzo, J., Kamali, R., Leblanc, R., Lunt, B., McGettrick, A., Sloan, R., \& Topi, H. (2005). ACM, AIS, IEEE Computing Curricula 2005. Retrieved August 12, 2013, from http://www.acm.org/education/education/curric vols/CC2005-March06Final.pdf/.

11. Spradling, C., \& Strauch, J. (2010). Implementing an interdisciplinary capstone experience for interactive digital media majors. Journal of Computing Sciences in Colleges, 25, 214-222.

12. Truman State University (2003). Assessment Almanac, Chapter XII: Capstone Experiences. Retrieved August 12, 2013, from http://assessment.truman.edu/almanac/2003/CH12.pdf.

13. West, M.A. (2012). Effective Teamwork: Practical Lessons from Organizational Research, 3rd Edition. West Sussex, England: John Wiley \& Sons. 